\title{
Docente-clínico: o complexo papel do preceptor na residência médica
}

\section{| ${ }^{1}$ Sérgio Henrique de Oliveira Botti, 2 Sérgio Tavares de Almeida Rego |}

Resumo: Este estudo analisa o papel do preceptor na residência médica, partindo das percepções dos preceptores dos programas de residência em especialidades clínicas de um hospital de ensino. Através de uma pesquisa descritiva, utiliza-se a técnica de entrevista não-diretiva, com o intuito de estudar o fenômeno a partir da fala de 16 desses preceptores. Utiliza-se a análise de conteúdo, tecendo uma relação com as referências da literatura. Percebe-se que o preceptor assume vários papéis. Encontram-se referências a orientador, tutor, supervisor e mentor. Ele planeja, controla, guia; estimula o raciocínio e a postura ativa; analisa o desempenho; aconselha e cuida do crescimento profissional e pessoal; observa e avalia o residente executando suas atividades; atua na formação moral. É grande a importância do preceptor como educador, oferecendo, ao aprendiz, ambientes que lhe permitam construir e reconstruir conhecimentos. $\mathrm{O}$ preceptor ensina realizando procedimentos técnicos e moderando a discussão de casos. Assume papel do docente-clínico, um profissional que domina a prática clínica e os aspectos educacionais relacionados a ela, transformando-a em ambiente e momento educacionais propícios. Identificando as oportunidades de aprendizagem e os cenários de exposição, o preceptor da residência médica funciona como uma vitrine de atributos técnicos e relacionais, proporcionando verdadeiras condiçôes de desenvolvimento técnico e ético nos cenários reais de prática profissional.

> Palavras-chave: preceptoria; residência médica; educação médica.

\author{
1 Doutor em Saúde Pública \\ pela Escola Nacional de \\ Saúde Pública Sérgio Arouca, \\ Fundação Oswaldo Cruz \\ (ENSP-FIOCRUZ); Comissão \\ de Residência Médica, \\ Universidade Federal de Juiz de \\ Fora-MG (COREME/HUUFJF). \\ Endereço eletrônico: botti@ \\ uai.com.br \\ 2 Doutor em Saúde Coletiva \\ pelo IMS-UERJ e pesquisador \\ titular, Departamento de \\ Ciências Sociais da ENSP- \\ FIOCRUZ. Endereço eletrônico: \\ rego@ensp.fiocruz.br
}


A residência médica é considerada o padrão-ouro dos cursos de especialização na área pelo Ministério da Educação (BRASIL, 2008) e se consolidou como a melhor forma de capacitação profissional para o médico em nosso meio (SAMPAIO, 1984). Ela pode ser analisada sob vários enfoques e em seus múltiplos fatores, dentre eles, o papel do preceptor. Na história da educação médica, podemos sempre notar a figura de um profissional mais experiente, que auxilia na formação profissional. Focalizando, então, a discussão nesse profissional mais experiente, que aqui chamamos de preceptor, buscamos compreender qual o seu papel na formação do médico residente e como ele o vê e se vê nesse processo de formação profissional. Percebemos que o estudo criterioso e sistemático da formação profissional é um dos principais caminhos para entendermos melhor a situação atual da residência médica e analisar os meios e estratégias que podem ser estabelecidos para estimular e promover mudanças (NUNES, 2003; REGO, 2004; VILLAR, 2002).

\section{Material e métodos}

Trata-se de uma pesquisa descritiva (TOBAR; YALOUR, 2003), que apresenta e discute as principais características da preceptoria, a partir da fala de alguns de seus atores. Estas falam além e através delas, e nos permitem interpretar o processo social a partir das pessoas envolvidas nele (GARRETT, 1974). Mostrando a percepção dos preceptores sobre seu papel na formação dos residentes, analisamos o processo de ensino-aprendizagem na residência médica em especialidades clínicas de um hospital de ensino. Buscamos, ainda, descrever a importância dada, pelos preceptores, a seu papel na formação da identidade profissional dos residentes. Optamos pela pesquisa de campo, realizada no local onde o fenômeno ocorre, buscando elementos para bem caracterizá-lo (TOBAR; YALOUR, 2003). Utilizamos a técnica de entrevista, pois ela permite uma rica interação entre pesquisador e entrevistado, ambos interferindo no conhecimento da realidade em questão. Lançamos mão da entrevista não-diretiva, que combina perguntas estruturadas com questões abertas e que, segundo Michelat (1982), permite que o entrevistado possa discorrer mais livremente sobre o tema proposto, assumindo o papel de explorador do tema, em função do que pensa e sente. Nesse tipo de entrevista, o entrevistador tem função maior de facilitador e de 
apoio. Há, ainda, maior possibilidade de se captar alguns aspectos subjetivos da realidade social dos entrevistados, através de suas percepções, significados e motivações, além de evidenciar suas atitudes e valores. Consideramos, então, os preceptores da residência como nossas unidades de análise, nosso objeto de pesquisa, para os quais apontamos nossa ferramenta de coleta e análise de dados (TOBAR; YALOUR, 2003).

Um dos autores também é preceptor em um programa de residência médica, o que facilitou nossa inserção no campo de estudo. Houve, contudo, extrema preocupação em obter o necessário distanciamento dos fatos, através do esforço racional para a realização das entrevistas e análise dos conteúdos. O campo de estudo compreendeu, então, os programas de residência em especialidades clínicas de um hospital de ensino. Consideramos especialidades clínicas todas as clínicas de adulto, excetuando-se as especialidades cirúrgicas e a ginecologia-obstetrícia.

Limitar o estudo a um hospital de ensino não significou perder a abrangência, mas teve a intenção de aprofundar a compreensão (MINAYO, 2000) do grupo social em questão, o grupo de preceptores. Como escolhemos um desenho de estudo do tipo descritivo, buscamos, no universo dos preceptores de um hospital de ensino, a maior heterogeneidade possível para chegarmos a certa representatividade de tipos específicos em nossa seleção (TOBAR; YALOUR, 2003). Procuramos incluir a maior diversidade de percepções sobre o assunto e, para tal, optamos por utilizar como variáveis de seleção: idade, sexo e tempo de exercício da preceptoria. Elas foram escolhidas por indicarem realidades potencialmente diferentes, nas quais os fenômenos de socialização acontecem também de maneiras díspares (MICHELAT, 1982).

Nosso universo foi formado pelos preceptores das áreas clínicas. Consideramos preceptores todos os profissionais médicos, com cargo de professor ou não, que trabalham diretamente com o residente e convivem com ele durante todo o período de sua formação.

Nesse hospital de ensino, o perfil dos 74 preceptores em 2008 (ano do estudo) é o seguinte: em relação à idade, 32\% têm de 31-40 anos, 26\% de 41-50, 31\% de $51-60$ anos e $11 \%$ de $61-70$ anos de idade. Não temos preceptores com menos de 31 anos, provavelmente pela inexistência de concursos para o cargo nos últimos anos no referido hospital. Destacamos ainda o fato de termos preceptores com idade entre 61-70 anos, período geralmente final da vida do profissional na 
instituição (GLUGOSKI, 2003). Não encontramos dados semelhantes em outra pesquisa sobre o mesmo tema (WUILLAUME; BATISTA, 2000). De acordo com o sexo, $70 \%$ são do sexo masculino e $30 \%$ do sexo feminino. Esses achados sobre a idade e sexo dos preceptores são semelhantes aos encontrados em pesquisa nacional sobre o docente do curso médico (BATISTA, 1998; CINAEM, 1997). Em relação ao tempo de exercício da preceptoria, 30\% exercem a preceptoria há até 10 anos, 38\% exercem-na de 10 a 20 anos e 32\% são preceptores há mais de 20 anos. Estas informações são coerentes com as apresentadas por Wuillaume (2000). Em relação à titulação acadêmica, 23\% dos preceptores têm mestrado, 27\% com doutorado e 50\% têm residência. Observamos que a metade dos preceptores tem a residência médica como sua maior titulação, dados também semelhantes aos achados em uma pesquisa nacional (BATISTA, 1998; CINAEM, 1997).

Foram selecionados 16 preceptores a partir das características já referidas e de acordo com a disponibilidade e interesse em participar da pesquisa. Foi utilizado o critério de saturação para definição de encerrar as entrevistas, ou seja, quando percebemos uma propensão à reincidência das falas. Deste total, quatro preceptores tinham entre 30-39 anos; seis preceptores, entre 40-49 anos; cinco preceptores entre 50-59 anos e um preceptor entre 60-69 anos de idade. Nove eram do sexo masculino e sete do sexo feminino. Esta distribuição de indivíduos por sexo não é a mesma observada na população, já que as entrevistas sugeriam que a diversidade de sexos proporcionava maior diversidade de respostas. Com relação ao tempo de preceptoria, quatro preceptores exerciam a preceptoria há até 10 anos, seis preceptores exerciam-na de 10 a 20 anos e também seis dos entrevistados eram preceptores há mais de 20 anos. Sete preceptores tinham doutorado, dois com mestrado e também sete preceptores tinham residência médica. Possivelmente relacionado ao tempo de preceptoria constatado, observamos uma elevada proporção de docentes com doutorado.

Foi elaborado um roteiro de entrevista que expressava, segundo Minayo (2000), nossas hipóteses, pressupostos e trazia uma "teoria em ato". Esse roteiro continha questôes sobre o papel do preceptor, o processo de formação e sobre a aprendizagem de habilidades técnicas e relacionais (atitudes e comportamentos) durante a residência médica. $\mathrm{O}$ trabalho recebeu a aprovação pelo Comitê de Ética em Pesquisa da Escola Nacional de Saúde Pública Sérgio Arouca. Apresentamos, previamente, o termo de consentimento livre e 
esclarecido a todos os entrevistados, que o leram com atenção e consentiram espontaneamente em participar do estudo. Gravamos as entrevistas, com a anuência dos preceptores, e depois as transcrevemos.

Para analisar nossas entrevistas, utilizamos a técnica de análise de conteúdo, conforme proposto por Bardin (1979), pelo rigor de sua objetividade e fecundidade da subjetividade, procurando o que está escondido, velado, não explicitado. Realizamos a leitura exaustiva das entrevistas, procurando organizar, operacionalizar e sistematizar nossas ideias para o desenvolvimento da análise. Essa etapa foi como um processo de impregnação (MICHELAT, 1982). Depois, começamos a codificar os dados, isto é, transformá-los sistematicamente e agrupá-los em unidades que permitissem uma boa descrição e representação do conteúdo dos textos. Utilizamos, então, a análise temática. Como resultado dessa classificação progressiva dos elementos dos textos, criamos os temas, as categorias de análise (RICHARDSON, 1999), a partir das quais começamos a tecer uma relação com as referências e com nossa percepção, buscando extrair desse tripé fala dos preceptores, pesquisador e literatura - aspectos essenciais ao tema.

Michelat (1982) relata que a rigidez na categorização dos textos, o isolamento das categorias a serem analisadas e o excesso de importância às frequências dessas unidades de análise podem trazer uma interpretação esfacelada da mensagem, com perda de conteúdos latentes. Ele ainda reforça que elementos importantes podem aparecer apenas uma vez. Considerando suas observações, buscamos permitir que todos os elementos do material analisado encontrassem seu lugar, numa análise do conjunto, podendo aparecer em muitos sítios ou unidades de significação. Tivemos ainda o cuidado de dar atenção especial a cada entrevista em sua singularidade, ao mesmo tempo em que relacionávamos as diversas entrevistas entre si, alternando leituras verticais e horizontais. Partimos para elaboração de um esquema explicativo inicial, que foi se modificando no decorrer da análise (MICHELAT, 1982).

Todo o nosso trabalho tem como base essa frutífera relação, porque acreditamos, como afirma Demo (2001), que não é a ciência quem conduz a realidade, mas exatamente o oposto. A realidade que é "interdisciplinar, dinâmica e fugidia" (DEMO, 2001, p. 33), que não pode ser confinada em nenhuma teoria, é analisada por vários olhares (todos parciais), e é quem realmente conduz a ciência. 


\section{Resultados e discussão}

Analisando os textos das entrevistas, trabalhamos com duas grandes categorias de análise: o processo ensino-aprendizagem na residência médica e o papel do preceptor nesse processo. Neste trabalho vamos descrever, dada as indispensáveis limitaçôes de espaço e a necessidade de uma abordagem de profundidade, nossas consideraçóes sobre apenas um desses eixos: o papel do preceptor. Chamamos os preceptores entrevistados de preceptor 1, preceptor 2 e assim sucessivamente, para mostrarmos suas falas.

\section{O papel do preceptor}

A definição do papel a ser desempenhado pelo preceptor ainda é assunto muito controverso na literatura científica e nos documentos oficiais, conforme apresentamos em ampla revisão da literatura (BOTTI; REGO, 2008), mostrando que mesmo documentos oficiais no Brasil atribuem funções diferenciadas a este profissional que aqui chamamos de "preceptor". Tal multiplicidade de funçôes também é percebida pelos preceptores quando se referem ao seu trabalho, como demonstraremos aqui. Quando os preceptores foram solicitados a definir essa função com apenas uma palavra, esta variação de significados fica bem evidente. Eles acreditam que um preceptor deve ser: orientador (quatro preceptores), exemplo (três preceptores), supervisor, tutor, guia, pai (dois preceptores), amigo, professor, moderador, facilitador, parceiro e educador (um preceptor). Notem que, embora solicitados a definirem com apenas uma palavra, alguns caracterizaram o papel do preceptor com mais de um vocábulo.

\section{O preceptor como orientador, supervisor, tutor, mentor}

$\mathrm{Na}$ concepção empirista do conhecimento, aprender e ensinar aparece com uma visão de que o conhecimento advém de alguém ou de algo fora do indivíduo, independentemente da vontade do mesmo, que se torna um sujeito passivo nesse processo (BECKER, 1993). Orientar, nas falas dos preceptores, parece muito com esse sentido empirista, de alguém, algo de fora ser capaz de mostrar o caminho, de guiar, pressupondo o indivíduo como uma tábula rasa, na qual o resultado de suas experiências são escritas. O Preceptor 9 acreditava ser necessário "moldar, encaminhando, orientando, mostrando ao residente os caminhos". Mas o mesmo termo orientar aparece com o sentido de estimular 
o raciocínio ou, como nos disse o Preceptor 2, de "fazer com que o residente

raciocine, tente achar o caminho". Aprender e ensinar, então, assumem um conceito relacionado ao construtivismo, permitindo que o residente assuma um papel ativo, observando as exposições, selecionando e fixando as informações, construindo seu conhecimento (SAVIANI, 2005; TEIXEIRA, 2000):

Supervisionar é outra função que percebemos com clareza. As características marcantes desse papel (CORDEIRO, 1968; HOUAISS, 2001; OXFORD, 2000) permeiam várias falas dos preceptores, muitas vezes não acompanhadas pelo vocábulo supervisor. Para o Preceptor 3, “o papel é de corrigir erros, se estão fazendo as condutas corretas". Esse sentido se relaciona com o de analisar o desempenho, vigiar. Já o Preceptor 5 acredita que deve "estar sempre gerenciando esse aprendizado", no sentido de planejar, controlar o processo.

Tutor não aparece nas exposições dos preceptores apenas como um guia, um facilitador, que auxilia no processo de aprendizagem centrado no aluno (DOLMANS, 2006; MAUDSLEY, 1999; WETZEL, 1996). Essa visão que a Aprendizagem Baseada em Problemas oferece, de um profissional focado no "aprender a aprender", pode gerar a falsa impressão que apenas habilidades pedagógicas são necessárias, minimizando ou desconsiderando as habilidades médicas (técnicas). É importante colocar que esse modelo de aprendizagem ainda não é considerado o modelo perfeito, sendo alvo de muitas críticas (BECKETT, 1985; EPSTEIN, 2004). Mas os preceptores associam as funções pedagógicas ao "como fazer", deixando claro que o profissional responsável pela formação do residente deve ter o domínio dessa habilidade. É o que nos mostra o Preceptor 12 , dizendo ser um

moderador, instrutor, organizador, indicando e auxiliando na busca de literatura adequada [...] fornecendo ao residente um subsídio de como seria a metodologia adequada [...] auxilia no diagnóstico diferencial de algumas manobras de exame físico. Nas dúvidas, às vezes, é preciso pegar na mão do residente para poder ensinar.

Um profissional mais experiente que guia, orienta e aconselha um jovem no início de carreira, e que tem ação primordial ao longo do crescimento pessoal e profissional, ultrapassando a orientação para estudo, é o mentor (BEAUCHESNE; HOWARD , 1996; BELLODI, 2003; BELLODI, 2005; FREEMAN, 2000). Esta compreensão também está presente nos relatos, compondo assim a função dos preceptores na sua própria visão, como nessa fala do Preceptor 3, que afirma que o preceptor deve "passar um pouco de nossa experiência [...] Preceptor é 
uma pessoa que tem mais experiência, já viveu situações que o residente está vivenciando, até mesmo como residente".

\section{O preceptor como um educador}

Educador tem, para nós, uma função de trocar, construir e reconstruir conhecimentos, num caminho que se trilha para formar pessoas ativas na sociedade a que pertencemos, comprometidas com essa sociedade e que percebem a importância de seus papéis profissionais na construção da cidadania (STRUCHINER; GIANNELLA, 2002). Nesse sentido, educar é muito diferente de treinar, que nos lembra um sentido preferencial de condicionar, adestrar (HOUAISS, 2001).

O preceptor tem um instinto de transmitir ao residente tudo que ele (o preceptor) sabe, mas isso é insuficiente para o verdadeiro aprendizado, não sendo o ideal porque não se foca no verdadeiro significado do aprender (TAYLOR, 2006). Várias características do preceptor, efetivo educador, são citadas na literatura (FURMEDGE, 2008; IRBY, 1992; IRBY, 1994; MEYERS et al., 2007; TAYLOR, 2006). Explicitar os pontos importantes do processo-ensino aprendizagem é uma maneira de tornar o residente mais ativo, mais independente, nessa construção (EDWARDS, 2002). Essa é um dos fatores que Meyers et al. (2007) acreditam importantes para um novo desenho da formação durante a residência médica. Irby (1992) chama esse importante componente da ação do preceptor de "diagnosticar a compreensão" do residente. Ampliar o conceito de educação na formação médica significa, então, passar de um processo de exclusiva aquisição de conhecimentos ou habilidades (baseado na exposição simples e pura de conteúdos e técnicas) para o desenvolvimento de uma consciência crítica profissional, com a qual o neófito aprende conteúdos, técnicas e, sobretudo, aprende a "pensar e detalhar" todos os aspectos profissionais (BLEAKLEY, 2006). Conseguimos detectar esses aspectos nas consideraçôes feitas pelo Preceptor 2, que achava ser sua função "explicitar os pontos importantes do aprendizado ao residente. $\mathrm{O}$ médico tem a função só de fazer, o preceptor tem que ensinar como fazer, como chegar".

Para o Preceptor 14, mostra-se importante

escolher cenários de exposição, ter capacidade de identificar quais são as oportunidades de aprendizagem [...] O preceptor é um educador. Temos preceptores excelentes técnicos, mas não educadores. Educar é proporcionar a alguém reais condiçōes de aprendizado. Uso uma expressão que é o docente-clínico. O que temos na verdade é 
o clínico pseudo-docente. Não compreende o processo educacional [...] Ou o faci-

litador não-clínico que, oficialmente, não tem que saber nada sobre aquele assunto específico, desde que tenha bons atributos de facilitação. Precisamos de docentes, educadores de verdade, e que tenham formação clínica. O preceptor é um docenteclínico, alguém com atributos de educador, com bagagem teórica muito grande e com excelente formação clínica.

Notamos aqui a expressão docente-clínico, que se aproxima muito do que Taylor (2006) utiliza como "clinical teacher", definindo bem quem o preceptor deve ser. Esse autor acredita que a centralidade da preceptoria está na relação estabelecida entre o docente-clínico e o aprendiz e no encontro de ambos com o paciente. Esse encontro deve se focar tanto no problema clínico que o paciente está enfrentando como também na maneira como o paciente percebe esse problema. Irby $(1992 ; 1994)$ também relata, entre as características essenciais do conhecimento do preceptor, o domínio da prática clínica e dos aspectos educacionais relacionados a ela. Tudo isso porque o preceptor atua na sua própria prática médica, trabalha como preceptor em ação, como médico e educador; ao desempenhar suas funções no cuidado à saúde do paciente, preocupa-se também com suas funções educacionais (IRBY, 1992). Aí está a importância de professores que sejam excelentes educadores e ótimos clínicos - os docentesclínicos, para conseguirmos uma formação médica de qualidade.

\section{O preceptor que ensina, realizando os procedimentos técnicos}

O Preceptor 1 afirmou que uma de suas funçôes é "voltar ao leito do paciente, repetir o método clínico, mostrando ao residente o que é importante". Se o preceptor é educador, mas também um bom clínico, ele deve dominar a execução de procedimentos técnicos, mostrando ao residente como se faz. Essa prática é considerada como um fator que melhora a aprendizagem (NEHRENZ, 2007) e também pode servir como uma resposta à advertência para que os preceptores não percam suas habilidades clínicas ao entrarem na vida acadêmica (TAYLOR, 2006). É ainda uma função que justifica a cobertura de todas as atividades dos residentes pelos preceptores, uma grande reivindicação em nosso meio e também em outros países (BANSAL, 2005). O papel de executar procedimentos clínicos é uma reafirmação de que não existe nenhuma contradição ou separação entre o exercício da preceptoria (educar) e a prática médica (execução de procedimentos). Pelo contrário, a execução de 
ambas as funções só podem e só têm lugar, na formação médica, se ocorrem conjuntamente, definindo a função de preceptor (EDWARDS, 2002).

Quando o Preceptor 2 afirmou que deve "ficar ao lado do residente para que ele tente fazer inicialmente[...] Caso não seja possível, o preceptor deve fazer o procedimento, o residente assiste então e vai fazer em outra oportunidade”, reforçou a necessidade de cobertura das atividades dos residentes pelos preceptores. A literatura nos informa pouco sobre os riscos, para os pacientes, de médicos em formação realizarem procedimentos para os quais ainda não estão totalmente preparados (SANTEN et al., 2004; FISCHER et al., 2006). Porém, alguns autores mostram que, quando os preceptores permitem menor ação do residente, aumenta a aderência aos consensos, ocorrem melhores mudanças nos planos terapêuticos e melhoram também os resultados finais. Isso permite concluir que diminuir a autonomia dos residentes melhora o cuidado aos pacientes e também a sua segurança (ERICSSON, 2004; KENNEDY et al., 2005). É preciso, então, preocupar-se com os aspectos técnicos e éticos dessa prática, mesmo sob preceptoria (SANTEN et al., 2004).

Uma constatação do Preceptor 10, defendendo que "um substrato teórico é necessário, o residente fica um período com o preceptor o tempo todo e, depois, começa a exercer as habilidades técnicas”, é corroborada pela literatura. Recomenda-se que o residente só execute procedimentos técnicos quando essa execução já tenha se transformado em uma ação automática, sem interrupções (ERICSSON, 2004). As habilidades motoras necessárias para realização desses procedimentos são adquiridas em três etapas. Num primeiro momento, a etapa cognitiva, o neófito consegue explicar e demonstrar o procedimento, mas não consegue desempenhá-lo sem desvios por inteiro. $\mathrm{Na}$ etapa integradora, o procedimento é repetido inúmeras vezes, com observações de preceptores, até conseguir executá-lo com técnica, livre de interrupçôes. Na terceira etapa, consegue executar o procedimento automaticamente, com técnica eficiente.

\section{O preceptor como moderador na discussão de casos}

Por outro lado, o Preceptor 12 achava que "não precisa executar atividades/ procedimentos para mostrar como se faz [...] o papel é de moderação, acompanhamento e orientação". Sobressai uma função de discutir os casos com os residentes, estimulando o raciocínio clínico. Dos 16 preceptores entrevistados, 
12 explicitaram essa função como a principal do preceptor. Irby (1992) também considera essa função primordial e relata que, para bem realizá-la, os preceptores baseiam seu raciocínio clínico e suas instruções em scripts mentais (NORMAN, 2005) que interagem com a improvisação. Isso é exigido pela necessidade de adaptação dos conhecimentos à prática clínica. Ou seja, na discussão de casos, o intelecto do preceptor, suas reflexôes e pensamento interativo para o diagnóstico, planejamento e condução da situação em questão, conecta-se com o exercício prático da medicina, num processo dinâmico da preceptoria.

Mas torna-se preocupante a informação dada pelo Preceptor 16 que disse evitar "executar ações para mostrar ao residente como se faz [...] acho fundamental que o residente pegue e faça [...]". Pois, como uma consequência desses pensamentos, notamos uma diminuição das oportunidades de treinamento de habilidades à beira do leito, com os residentes observando os preceptores coletando a história clínica, executando o exame físico ou outros procedimentos técnicos e aplicando seus conhecimentos na tomada de decisões (AHMED, 2002; RAMANI et al., 2003; GUARINO et al., 2006). As discussões clínicas, distantes do paciente, têm sido a tônica da formação médica, com foco principal nos exames laboratoriais e de imagem.

Podemos notar, ainda nas entrevistas, que existe discordância sobre a importância, ou mesmo sobre a existência desse papel de observar o residente executando suas atividades. Isso é também relatado na literatura, chamando-se a atenção para a perda de oportunidade de oferecer feedback ao residente e para o perigo da desconsideração de possíveis erros nas condutas com os pacientes (FEDDOCK, 2007; HOLMBOE et al., 2001; NOEL et al., 1992; RAMANI et al., 2003). Retornamos então à questão ética da formação dos residentes. Santen et al. (2004) publicaram um artigo que discute as percepçôes dos pacientes sobre serem "utilizados" nesse treinamento e as dificuldades sobre essa discussão, que incluem desde a compreensão do sistema de treinamento da residência médica pelo paciente, até a consciência dos mesmos que estarão sendo atendidos por médicos em formação. Os autores determinam três pontos fundamentais: a capacidade de compreensão de todos os pacientes, a vontade de ser/servir como voluntário e a informação oferecida pelo residente sobre os procedimentos que irão realizar e sobre sua experiência nessas atividades. Com essa discussão, introduzimos o papel do preceptor na formação moral do residente. 


\section{O preceptor na formação moral}

O Preceptor 1 nos lembra que tem papel "na ética, no profissional, no coletivo. Quando se trabalha com residentes em hospital, é preciso ensinar a respeitar o paciente, o colega, a enfermagem, a bioquímica". O Preceptor 4, seguindo a mesma linha, acredita que "temos que ensinar o bom relacionamento com o próprio preceptor, com a enfermagem, com o paciente e com os colegas". Ponderamos, porém, que não conseguimos ensinar a respeitar ou a desenvolver um bom relacionamento. Não no sentido tradicionalmente compreendido de ensinar. Podemos contribuir para que o indivíduo respeite o outro e assim construa bons relacionamentos em sua vida profissional, dentro das concepções defendidas, por exemplo, por Rego (2003)

Percebam que o Preceptor 2 afirmou que "atua nos comportamentos e atitudes [...] Relacionamentos com a família do paciente, com as pessoas, com o paciente, com situaçôes”. Mas não estamos convencidos de como se dá essa atuação. Sabemos que, na socialização profissional, existe uma aprendizagem das técnicas e dos conhecimentos específicos, assim como de atitudes, valores e padrões de comportamento (PATEY, 2008) e que esse aprendizado se baseia no envolvimento com a comunidade da escola médica formada por preceptores, profissionais de saúde, estudantes e pacientes (MERTON, 1957). Podemos pensar, então, que essas mençôes sobre o papel do preceptor são relatos de sua função nesse currículo oculto, propiciando condições e ambientes nos quais se estimule a percepção e o respeito ao outro.

Mas qual a ação efetiva do preceptor nessa formação? É preciso esclarecer que, apesar desse papel do preceptor, o residente não é passivo nesse processo, apenas recebendo influências. Com sua bagagem, seu espaço social e os conteúdos interiorizados na socialização primária, seu habitus (BOURDIEU, 2007), o residente é o ator principal. Livre para escolher entre tudo que escola médica lhe oferece, mas também sofrendo certa coação a seguir um padrão mínimo de conhecimentos, valores e atitudes típicas da corporação médica (REGO, 2003).

O Preceptor 1, em suas considerações sobre formação moral, afirmou:

no ensino da ética, o principal papel do preceptor é mostrar como se faz na prática. Você leva o residente com você e ele vê como você conversou, depois ele repete as orientações numa mesma situação posteriormente [...] a gente tem que trabalhar melhor e é na prática, dando o exemplo. 
Reforça o papel do exemplo e é apoiado pelo Preceptor 5, que afirma:

o papel do preceptor é seguir e demonstrar uma diretriz básica de conduta [...] uma diretriz de trabalho. Estar empenhado em resolver a situação do paciente da melhor maneira possível e atuar de maneira firme, mas sem conflito, com outros colegas [...] Essa é a melhor maneira que o preceptor tem de ensinar atitudes, isto é, basicamente através do exemplo.

Mas é importante que a formação moral na residência médica não seja centrada na discussão do código de ética ou na apresentação de modelos idealizados, mostrando uma moral exclusivamente heterônoma, baseada no seguimento de normas e princípios pré-estabelecidos, na ética deontológica (ARMITAGE; BURNARD, 1991). Notamos, contudo, esses relatos do papel do preceptor que explicitam o ensino da ética deontológica e baseada no exemplo do preceptor, não reconhecendo o protagonismo pessoal nas escolhas que faz e no processo cognitivo e afetivo relacionado com o desenvolvimento moral.

Esse tipo de ensino da ética deontológica discute apenas a moralidade do agente. Precisamos de um ensino baseado na reflexão crítica dos atos, frente aos dilemas e às relações sociais cotidianos da prática médica, respeitando um contexto real (REGO et al., 2004). O Preceptor 10 mostrou sua preocupação em "saber orientar melhor as atitudes e comportamentos, baseado em algo escrito e sedimentado, e menos em sua própria experiência”. Patey (2008) afirma que o melhor cenário para ensino das habilidades éticas é o próprio local de trabalho, através da observação e discussão dos comportamentos e atitudes e do oferecimento de feedback pelos preceptores. O Preceptor 16 acreditava que "devemos assentar e conversar. Deixar que os residentes vivenciem os conflitos e ficar do lado, dando suporte”. É neste contexto que podemos compreender o papel passível de ser desempenhado pela Bioética na formação médica, lembrando que Bioética deve ser considerada (REGO, 2003) como o campo que questiona o caráter absoluto e fora de contexto dos valores morais tradicionais, dos direitos e dos princípios. Esse questionamento é feito através do diálogo, do respeito às diferenças e de acordos e consensos.

Destacamos duas observações de preceptores entrevistados: "devemos avaliar as atitudes do dia a dia [...] uns sabem muito de livro, mas não sabem conversar com os pacientes, têm uma relação médico-paciente muito, muito conturbada, defeituosa [...] você consegue ver isso, qual residente tem posturas mais adequadas" (Preceptor 1) e "deve existir avaliação das atitudes, devem-se criar 
mecanismos para isso. É importante fazer, o problema é como fazer" (Preceptor 3). Aqui é possível notar que os preceptores reconhecem que o "ensino" da ética aos residentes é uma de suas funções, mesmo que não saibam exatamente como. Avaliar a aquisição de atributos também é um papel relatado pelo Preceptor 14, que considerou ser necessário

verificar se o residente está desenvolvendo os atributos técnicos e relacionais necessários, cobrar o desenvolvimento dos atributos necessários [...] servir como um avaliador, cobrando o desenvolvimento de atributos, dando um retorno, oferecendo uma informação se o processo está caminhando da maneira adequada. $\mathrm{O}$ aprendiz precisa de retorno, precisa saber se está fazendo a coisa certa, se não, a coisa fica muito no ar.

Notamos, então, a importância conferida à formação moral através de suas preocupações em avaliar os comportamentos e atitudes dos neófitos, assim como através da explicitação de que esses atributos relacionais são essenciais para a construção de uma melhor prática médica.

Finalizando nosso eixo temático, podemos afirmar que ensinar as habilidades relacionais, que compreendem a formação ético-moral, ao mesmo tempo em que se preocupa com o desenvolvimento dos atributos técnicos é o grande desafio dos preceptores (PATEY, 2008).

O Preceptor 14, em sua entrevista, caracteriza o preceptor como aquele que

atua trabalhando em ação (seja lá o que for que se faça: ambulatório, centro cirúrgico, sala de hemodinâmica, sala de endoscopia, etc.). Mas o que o preceptor deve tentar passar pra quem ele está orientando e chamar a atenção para isso, acho que são os atributos. Todos os atributos, desde pontualidade, roupa, maneira de lidar com a pessoa até os atributos para colocação em prática de determinada técnica profissional. Acho que esse é o grande papel do preceptor, e isso é muito difícil, isso não é simples [...] Servir como uma vitrine de atributos, um estímulo, mostrando como se faz [...] o preceptor deve encarar os dois lados da moeda. Ele deve se sentir responsável pela exposição de atributos relacionais e pela exposição de técnicas, simultaneamente. Essa deve ser a atitude do preceptor

Assim, percebemos eco na literatura científica que nos mostra a própria prática clínica diária como o momento e local adequados para essa formação conjunta (THE CCT IN ANAESTHESIA I, 2008), sem a necessidade de recorrer a artificialidades. Essa é a riqueza da residência médica. O preceptor que atua atendendo pacientes e, ao mesmo tempo, educando os residentes, deve estar atento para discussão dos aspectos morais desse cuidado, baseado na "caixa de ferramentas" da bioética (REGO et al., 2004). Atuar na fusão dessas frentes, na ação diária como médico e educador, relacionando-se com pacientes e residentes, 
preocupando-se com a formação técnica e ética compreendem a ação do preceptor

em plenitude. Segundo Patey (2008), o preceptor consegue, então, a possibilidade de utilizar e ensinar atributos técnicos e morais no próprio momento da ação.

\section{Conclusão}

As considerações dos preceptores sobre o seu papel nesse processo foram trazidas por esse estudo. Analisamos e interpretamos suas falas, identificando suas relações com essa modalidade de pós-graduação, conhecendo e fazendo-os conhecer um pouco mais de sua realidade educacional.

O preceptor assume vários papéis no processo de formação da residência médica. Algumas vezes mostra o caminho, serve como guia. Outras, estimula o raciocínio e a postura ativa do residente. Muitas vezes planeja, controla o processo de aprendizagem e analisa o desempenho. Mas também aconselha, usando de sua experiência, cuidando do crescimento profissional e pessoal do jovem médico. Aqui percebemos a interação que o conceito de preceptor tem com orientador, supervisor, tutor e mentor.

A grande maioria das vezes o preceptor tem o papel de moderador na discussão de casos, estimulando o raciocínio clínico. Ele utiliza sua bagagem intelectual, suas reflexões baseadas na experiência para desenvolver e estimular o desenvolvimento, pelos residentes, da condução adequada da situação em questão. Essas discussões não devem ser distantes dos pacientes, o que diminuiria as oportunidades do residente para desenvolver habilidades à beira do leito e observar o preceptor em ação. Outra função do preceptor é observar o residente executando suas atividades. Essa postura permite oferecer feedback adequado ao neófito, além de levar em consideração a deteç̧ão de possíveis erros nas condutas com os pacientes.

Nesse ponto, torna-se imprescindível pontuar a ação do preceptor na formação moral do residente. $\mathrm{O}$ preceptor não tem papel exclusivo de exemplo, modelo. $\mathrm{O}$ exemplo é importante por ser um importante estímulo para a ação, mas uma de suas funções é explicitar e discutir valores que humanizam as relações. Estimular o desenvolvimento da consciência crítica, questionando e gerando conflitos cognitivos para, então, esperarmos o amadurecimento de sua competência moral. Para que a formação ética não se transforme numa transmissão de valores e códigos, o preceptor deve utilizar das situações diárias de seu próprio local de trabalho, observando e discutindo os comportamentos e atitudes com o residente. 
No entanto, o preceptor tem a função primordial de educador. Inicialmente ele identifica as oportunidades de aprendizagem, os cenários de exposição, tornando sua prática uma possibilidade para ensinar ao residente. Não atua apenas um facilitador, pois é também um bom médico. Ele mostra ao residente como se faz. Então funciona como uma vitrine de atributos técnicos e relacionais, tendo habilidades pedagógicas, o que o permite trocar e construir conhecimentos, contribuindo para a formação de cidadãos. Seu grande desafio é, então, proporcionar verdadeiras condições de desenvolvimento técnico e ético nos cenários de prática.

Além de todos esses papéis, é ainda função do preceptor avaliar o residente nas questōes morais e técnicas da prática profissional, oferecendo um retorno sobre seu desenvolvimento e sinalizando se o médico em formação está ou não no caminho certo.

Terminamos com a preocupação constante de termos explicitado, através das falas dos entrevistados, nossa visão do processo ensino-aprendizagem e do papel do preceptor na residência médica. Parafraseando Pierret (1999, p. 311), para quem "esses homens não falam em nome de uma geração, mas em seu nome para uma geração", diríamos que, com este estudo, não falamos em nome dos preceptores, mas para uma geração de preceptores e residentes envolvidos na melhoria de todo processo de formação médica.

\section{Referências}

AHMED, M.E.K. What is happening to bedside clinical teaching? Medical Education, v. 36, p. 1185-1188, 2002.

ARMITAGE, P.; BURNARD P. Mentors or preceptors? Narrowing the theory-practice gap. Nurse Education Today, v. 11, n. 3, p. 225-229, 1991.

BANSAL, A. Twenty-Four-Hour Attending Physician Coverage and Its Impact on Resident Training. Journal of the American College of Radiology, v. 2, n. 7, p. 642-644, 2005.

BARDIN, L. Análise de conteúdo. Lisboa: Edições 70, 1979.

BATISTA, N.A.; SILVA, S.H.S. O professor de medicina: conhecimento, experiência e formação. São Paulo: LOYOLA; 1998, 181p.

BEAUCHESNE, M.A, HOWARD, E.P. An investigation of the preceptor as potential mentor. The Nurse Practicioner, v. 21, n. 3, p. 155-159, 1996. 
BECKER, F. A epistemologia do professor: o cotidiano da escola. Petrópolis: Vozes, 1993.

BECKETT, C.; WALL, M. Role of the clinical facilitator. Nurse Educacion Today, v .5, p. 259-262, 1985.

BELLODI, P.L. O que é um tutor? Representações do papel em um grupo de professores de medicina durante o processo de seleção. Revista Brasileira de Educação Médica, Rio de Janeiro, v. 27, n. 3, p. 205- 212, 2003.

BELLODI, P.L.; MARTINS, M.A. Tutoria: mentoring na formação médica. São Paulo: Casa do Psicólogo, 2005, 370p.

BLEAKLEY, A. Broadening conceptions of learning in medical education: the message from teamworking. Medical Education, v. 40, p. 150-157, 2006.

BOTTI, S.H.O.; REGO, S. Preceptor, supervisor, tutor e mentor: quais são seus papéis? Revista Brasileira de Educação Médica, Rio de Janeiro, v. 3, n. 3, p. 363-373.

BOURDIEU, P. O poder simbólico. Rio de Janeiro: Bertrand Brasil, 2007.

BRASIL. Ministério da Educação. Secretaria de Ensino Superior. Residência Médica Lato sensu. Disponível em: <http://portal.mec.gov.br/sesu>. Acesso em: 30 jul.2008.

CINAEM. Relatório geral 1991-1997. Avaliação do ensino médico no Brasil. Brasília: CINAEM, 1997.

CORDEIRO, L.L. Relações industriais versus supervisão. Revista de Administração e Economia, São Paulo, v. 8, n. 28, p. 95-112, 1968.

DEMO, P. Pesquisa: método e cidadania. Ser Social, Brasília, v. 9, p. 33-52, 2001.

DOLMANS, D.H.J.M. et al. The relationship between professional behaviour grades and tutor performance ratings in problem-based learning. Medical Education, v. 40, p. 180-186, 2006. DUFFY, F.D.; HOLMBOE, E.S. What Procedures Should Internists Do? Annals of Internal Medicine, v. 146, p. 392-393, 2007.

EDWARDS, J.C. et al. Residents' teaching skills. New York: Springer, 2002.

EPSTEIN, R.J. Learning from the problems of problem-based learning. BioMedCentral Medical Education, v. 4, n. I, 2004. Disponível em http://www.biomedcentral.com/14726920/4/1. Acesso em: 24 nov. 2008.

ERICSSON, K.A. Deliberate Practice and the Acquisition and Maintenance of Expert Performance in Medicine and Related Domains. Academic Medicine, v. 79, n. 10, p. S70-S81, 2004. FEDDOCK, C.A. The Lost Art of Clinical Skills Christopher. American Journal of Medicine, v. 120, n. 4, p. 374-378, 2007.

FISCHER, M.A. et al. Learning from Mistakes: Factors that Influence How Students and Residents Learn from Medical Errors. Journal of General Internal Medicine, v. 21, n. 5, p. 419-423, 2006. 
FREEMAN, R. Faculty mentoring programmes. Medical Education, v. 34, p. 507-508, 2000. FURMEDGE, D.S. Apprenticeship learning models in residents: are they transferable to medical students? Medical Education, v. 42, p. 856-857, 2008.

GARRETT, A. A entrevista, seus princípios e métodos. Rio de Janeiro: Agir, 1974. 239p.

GLUGOSKI, M. Cultura, ciência e universidade. Jornal da USP, São Paulo, v. 642, p. 13, 2003. GUARINO, C.M. et al. Impact of instructional practices on student satisfaction with attendings' teaching in the inpatient component of internal medicine clerkships. Journal of General Internal Medicine, v. 21, p. 7-12, 2006.

HOLMBOE, E.S. et al. S. The effectiveness of a focused educational intervention on resident evaluations from faculty: a randomized controlled trial. Journal of General Internal Medicine, v. 16, p. 427-434, 2001.

HOUAISS, A.; VILLAR, M.S. Dicionário Houaiss da Lingua Portuguesa. Rio de Janeiro: Objetiva, 2001.

IRBY, D.M. How attending physicians make instructional decisions when conducting teaching rounds. Academic Medicine, v. 67, p. 630-638, 1992.

IRBY, D.M. What clinical teachers in medicine need to know. Academic Medicine, v. 69, p. 333-342, 1994.

KENNEDY, T. et al. Progressive independence in clinical training: a tradition worth defending? Academic Medicine, v. 80 (Suppl), p. 106-110, 2005.

MAUDSLEY, G. Roles and responsibilities of the problem based learning tutor in the undergraduate medical curriculum. British Medical Journal, v. 318, p. 657-661, 1999.

MERTON, R.K. et al. The student-physician. Introductory studies in the sociology of medical education. Cambridge: Harvard University Press, 1957.

MEYERS FJ, et al. Redesigning Residency Training in Internal Medicine: The Consensus Report of the Alliance for Academic Internal Medicine Education Redesign Task Force. Academic Medicine, v. 82, p.1211-1219, 2007.

MICHELAT, G. Sobre a utilização da entrevista não-diretiva em sociologia. In:

Crítica metodológica, investigação social e enquete operária. São Paulo: Polis, 1982, p. 191-211.

MINAYO, M.C.S. O desafio do conhecimento: pesquisa qualitativa em saúde. 7. ed. São Paulo: HUCITEC; 2000, 269p.

NEHRENZ, G. Preceptorship: Methods of teaching in the clinical arena; A commentary. The Internet Journal of Allied Health Sciences and Practice. Jan 2007. Volume 5 Number 1. Disponível em <http://ijahsp.nova.edu>. Acesso em: 30 jul. 2008.

NOEL, G.L. et al. How well do internal medicine faculty members evaluate the clinical skills of residents? Annals of Internal Medicine, v. 117, p. 757-765, 1992. 
NORMAN, G. Research in clinical reasoning: past history and current trends. Medical Education, v. 39, p. 418-427, 2005.

NUNES, M.P.T. Residência médica no Brasil - situação atual e perspectivas. Boletim Informativo da Associação Brasileira de Ensino Médico, Rio de Janeiro, v. XXXI, n. 6, 2003.

OXFORD UNIVERSITY PRESS. Oxford Advanced Learner's Dicitionary of Current English. Oxford: Oxford University Press, 2000.

PATEY, R.E. Identifying and assessing non-technical skills. The Clinical Teacher, v. 5, p. 40-44, 2008.

PIERRET, J. Contexto social, condiçôes da pesquisa e postura dos entrevistados. Caderno CRH, v.30/31, p. 297-318, 1999.

RAMANI, S. et al. Whither bedside teaching? A focus-group study of clinical teachers. Academic Medicine, v.78, p. 384-390, 2003.

REGO, S. A formação ética dos médicos: saindo da adolescência com a vida (dos outros) nas mãos. Rio de Janeiro: Fiocruz, 2003, 169p.

REGO, S. et al. Ensino da bioética nos cursos de graduação em saúde. In: . Educação Médica em transformação: instrumentos para a construção de novas realidades. São Paulo: Hucitec, 2004, p.165-185.

RICHARDSON, R.J. Pesquisa social: métodos e técnicas. São Paulo: Atlas, 1999.

SAMPAIO, S.A.P. A implantação da residência médica no Hospital das Clínicas: 40 anos de história. ESTUDOS FUNDAP. Residência Médica, São Paulo, p. 4-32, 1984.

SANTEN, S.A. et al. Patients' Willingness to Allow Residents to Learn to Practice Medical Procedures. Academic Medicine, v. 79, p. 144-47, 2004.

SAVIANI D. As concepções pedagógicas na história da educação brasileira. Agosto 2005. Disponível em: <http://www.histedbr.fae.unicamp.br/navegando/artigos_titulos.html>. Acesso em: 10 dez. 2007.

STRUCHINER M.; GIANNELLA, T.R. Formação de profissionais de saúde e educação à distância: elementos fundamentais In: PROFAE: educação profissional em saúde e cidadania. Brasília: Ministério da Saúde, 2002. p. 1-21.

TAYLOR, R.B. Academic Medicine: a guide for clinicians. New York: Springer, 2006.

TEIXEIRA, A. Pequena introdução à filosofia da educação: a escola progressiva ou a transformação da escola. Rio de Janeiro: DP\&A, 2000.

THE CCT IN ANAESTHESIA I: General Principles p. 29. Disponível em: http://www. rcoa.ac.uk/docs/CCTpti.pdf.Acesso em 23 nov. 2008.

TOBAR, F.; YALOUR, M.R. Como fazer teses em saúde pública: conselhos e ideias para formular projetos e redigir teses e informes de pesquisas. Rio de Janeiro: Fiocruz, 2003. 170p. 
VILLAR, M.A.M.; CARDOSO M.H.C.A. Residência médica em pediatria: no campo de prática. Cadernos de Saúde Pública, Rio de Janeiro, v. 18, n. 1, p. 329-339, 2002.

WETZEL, M.S. Developing the role of the tutor /facilitator. Postgraduate Medical Journal, v. 72, n. 850, p. 474-477, 1996.

WUILlAUME, S.M. O processo ensino-aprendizagem na Residência Médica em Pediatria: uma análise, 2000. 166f. Tese (Doutorado em Saúde da Criança e da Mulher) - Instituto Fernandes Figueira, Fundação Oswaldo Cruz, Rio de Janeiro, 2000.

WUILLAUME, S.M.; BATISTA, N.A. O preceptor na residência médica em pediatria: principais atributos. Jornal de Pediatria, Rio de Janeiro, v.7 6, n.5, p. 333-3388, 2000. 


\section{Clinical teacher: the complex role of the preceptor in medical residency}

This study examines the role of preceptor in the medical residency program, based on the perceptions of preceptors in clinical specialties of a university hospital. Through a descriptive research, it uses the technique of non-directive interview, to study the phenomenon from the speech of 16 preceptors. It uses the content analysis, weaving a relationship with the literature. It is perceived that the tutor takes on several roles. There are references to the tutor, supervisor and mentor. He plans, manages, guides; stimulates thinking and active attitude; observes the performance; advises and looks after the professional and personal growth; observes and evaluates the resident running its activities; acts in the moral formation. The importance of the preceptor as an educator is great, offering the learner environments, enabling it to construct and reconstruct knowledge. The preceptor teaches performing technical procedures and moderating the discussion of cases. Heassumes role of teacher-clinician, a professional who dominates the clinical practice and educational aspects related to it, making it a suitable educational environment and time. Identifying learning opportunities and exposure scenarios, the medical residency preceptor serves as a showcase of technical and relational attributes, providing real opportunities for developing actual technical and ethical scenarios for professional practice.

Key words: preceptorship; residency; medical education. 